\title{
Symmetry and selective attention: A dissociation between effortless perception and serial search
}

\author{
CHRISTIAN N. L. OLIVERS and PETER A. VAN DER HELM \\ University of Nijmegen, Nijmegen, The Netherlands
}

\begin{abstract}
It is widely assumed that symmetry is an important visual primitive, probably encoded without the need for attention. Julesz's (1981) definition of effortless perception, which states that any stimulus property perceived for exposure durations of $160 \mathrm{msec}$ or less is detected preattentively, contributed greatly to this belief. Single pattern studies confirm that symmetry is detected within this limit. In the present study, however, Julesz's operationalization is compared with the multiple pattern visual search task, to see whether symmetry as a wholistic property is detected in parallel. The results show that symmetry detection times are highly dependent on the number of distractor patterns. The findings are similar for dot patterns, wire polygons, solid block shapes, and simple parentheses. We conclude that symmetry detection per se requires selective attention, but that some related grouping or segmentation mechanism may operate preattentively.
\end{abstract}

Mirror symmetry (henceforth, symmetry) has been considered to be one of the most salient visual regularities for a very long time. Often referred to in the research literature are the Gestaltists, who incorporated symmetry in one of their laws (see Pomerantz \& Kubovy, 1986), or, even further back, Pascal (1658/1950, p. 491), who stated that "symmetry is what you see at a glance" (as cited, e.g., in Baylis \& Driver, 1994). The present study is concerned with this glance. In more specific (and more modern) terms: Is symmetry detected preattentively, or is scrutiny by means of selective attention required?

Up to now, the relationship between symmetry and attention has been far from clear. On the one hand, symmetry could serve as a strong nonaccidental object cue or figure-ground cue (Baylis \& Driver, 1994; Biederman, 1987; Donnelly, Humphreys, \& Riddoch, 1991; Driver, Baylis, \& Rafal, 1992; Koffka, 1935; Marr, 1982; Rock, 1983; Vetter \& Poggio, 1995; Wagemans, 1993) and, if detected preattentively, could thus aid efficient allocation of selective attention to relevant objects. Indeed, within machine vision, symmetry has been used as a cue for orienting attention (Yeshurun, Reisfeld, \& Wolfson, 1992). On the other hand, symmetry perception involves the detection of often complex combinations of spatial relationships about the axis, and, if symmetry is to guide the visual system toward relevant objects, these combinations should be extracted at an early stage. Results from attention research, however, suggest that the visual system may not be able to detect even much simpler spa-

We are grateful to Jan Theeuwes, Johan Wagemans, and Jeremy Wolfe for their useful comments on an earlier version of this paper. Thanks also to Johan Hulleman for fruitful discussions. Chris Olivers, to whom correspondence should be addressed, is now at the School of Psychology, University of Birmingham, Birmingham B15 2TT, England (e-mail: c.n.olivers@bham.ac.uk). tial relations (so-called conjunctions) without invoking selective attention (see, e.g., Enns, 1990; Treisman \& Gelade, 1980; Treisman \& Schmidt, 1982).

So far, the general opinion in the symmetry research field seems to favor the preattentive view (see Wagemans, 1995, for a review). Most influential has been Julesz's (1981, p. 28) definition of effortless perception, which states that a stimulus characteristic is detected preattentively if perceived under stimulus exposure durations of "less than $160 \mathrm{msec}$." The basic idea is that a time period of $160 \mathrm{msec}$ does not allow for a focused attentional scan by means of eye movements. On the basis of this definition, Julesz earlier (1971) argued that attention was not required in order to perceive symmetry in his well-known complex random dot patterns. Indeed, in many subsequent studies of symmetry detection, single patterns were presented tachistoscopically, with presentation times ranging from $10 \mathrm{msec}$ (Locher \& Wagemans, 1993) to $150 \mathrm{msec}$ (see, e.g., Barlow \& Reeves, 1979), and many values in between. It is generally found that symmetry perception occurs rather effortlessly within Julesz's limit.

Julesz's operationalization of preattentive perception seems to have gained sway from many attention models, including his own (see, e.g., Broadbent, 1958; Bundesen, 1990; Duncan \& Humphreys, 1989; Julesz, 1971; Treisman \& Gelade, 1980; Wolfe, 1994). All these models, in one way or another, propose that the visual input first enters a fast, parallel stage, called preattentive. The visual system then makes a selection from this parallel input by means of what is defined as selective attention. Selective attention is assumed to operate in a serial fashion - that is, it moves, or disengages and re-engages, from one part of the visual field to the other. We will stick to this dichotomy between a parallel preattentive stage and a serial selection mechanism, although it should be noted that Mack, Tang, Tuma, Kahn, and Rock (1992) have argued that this classic distinction is not appropriate for the tasks 
discussed here. More correct would be to speak of divided versus focused attention. We agree, but for the sake of convention we stick to the former distinction. It could be helpful to read preattentive as preselective.

The findings by Julesz and others (see, also, Baylis \& Driver, 1994) seem to confirm that, at least within symmetric patterns or objects, selective attention need not be deployed - that is, symmetry is probably not perceived through a scrutinous point-by-point comparison of elements across the axis but by a parallel mechanism. In the present study, we investigated whether symmetry is detected in parallel across patterns as well. That is, we wondered whether the pattern, instead of its elements, needs selection in order for its symmetry to be detected. After all, symmetry is a property of a pattern as a whole: Its structure is derived from the combination of relationships between its elements and not from the elements as such. We believe a full description of the interaction between symmetry and attention requires a look at this wholistic level, because only if symmetry as a whole is detected in parallel can it be helpful in rapidly guiding the visual system toward possibly relevant objects.

The popular multiple item visual search paradigm seems to be the most straightforward way to test whether symmetrical patterns need to be selected in order for their symmetry to be detected. The single pattern paradigm, applied so far, is inappropriate, because the single abrupt onset of the stimulus (often at fixation) confounds the pattern with the focus of attention (see, e.g., Posner, 1980; Yantis \& Jonides, 1984). In the standard visual search task, however, multiple items appear at once, and, thus, there is no confounding in terms of fixation or attentional capture effects. Usually, on half the number of trials, a target item, distinguished by a certain feature, is included. Also the number of items (the display size) is systematically varied. The subject must decide as quickly as possible on the presence of the target. If search slopes (display size $\times$ response time [RT]) turn out to be flat, it is assumed that the target feature is detected without the need for further selection (i.e., in parallel). If, however, RTs linearly increase with the display size, it is assumed the subject had to select a limited amount of information (items) at a time (see, e.g., Treisman \& Gelade, 1980).

There are some suggestions that symmetry is indeed a feature that should yield flat search slopes. For instance, Biederman (1987, pp. 117-119) considers symmetry to be one of the most important nonaccidental properties and explicitly suggests that it should be picked up in parallel from a search display. Furthermore, Pomerantz and his colleagues put forward that symmetry might be an important emergent feature (see, e.g., Pomerantz \& Garner, 1973; Pomerantz \& Pristach, 1989; Pomerantz, Sager, \& Stoever, 1977). Pomerantz mainly used a speeded classification task, from which typical stimuli (parentheses pairs) are shown in Figure la. The subject had to rapidly classify one (e.g., the left) member of a parentheses pair, whereas the other member was completely irrelevant. Still, Pomerantz and colleagues found that performance was affected by the irrelevant member: RTs increased when it was inconsistently varied but decreased when it was held constant or varied consistently. This indicates that some wholistic property of the combined elements is processed first--in other words, selective attention is prevented from having direct access to the individual element because the subject chooses to attend to an emergent feature of the entire configuration. ' Pomerantz mentions some specific spatial configurations as good candidates for emergent features-for example, (( and ( ) in Figure la. These configurations typically show closure, continuity, and symmetry (Pomerantz et al., 1977; see also Clement \& Weiman, 1970, for similar results with dot patterns). Pomerantz (e.g., Pomerantz \& Pristach, 1989) emphasizes the relationship to visual search tasks (viz., Treisman \& Paterson, 1984; see Figure 1c), suggesting that these properties should emerge in parallel from a multiple item display. The important point for now is that symmetry may be one of them.

\section{Overview of the Experiments}

In the present study, we investigated whether a salient isolated symmetry (i.e., a symmetry perceived within Julesz's limit) would also constitute a salient emergent

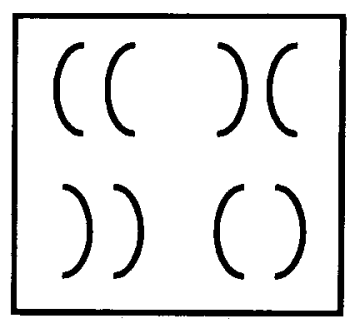

a
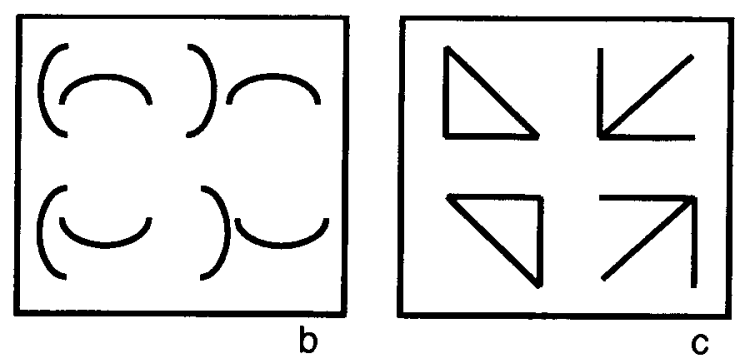

Figure 1. The stimulus types used by Pomerantz and colleagues (adapted from Pomerantz $\&$ Pristach, 1989). The parentheses configurations in (a) show grouping or emergent feature effects, whereas the configurations in (b) do not. The line segments in (c) form salient arrow junctions and even more salient closed triangles. Treisman and Paterson (1984) found "popout" effects with the latter stimuli as targets. 
feature among multiple items (i.e., in a visual search task). Each experiment consisted of two parts. In the first, tachistoscopic part, we presented single patterns for 120 msec. The task was to decide whether a pattern was symmetrical or asymmetrical. In the second, visual search part, we presented multiple patterns at once, including, for instance, a symmetrical target. The subject had to decide on the presence of this target. In both tasks, we measured accuracy and RTs.

The predictions were as follows: If symmetry requires attention to be focused on the pattern, search functions should show steep slopes, indicating serial search. If, however, symmetry is a highly salient visual primitive (i.e., if a symmetric pattern pops out among nonsymmetric patterns), slopes should be flat, suggesting parallel (preattentive) detection.

All four experiments were basically the same in setup. They differed mainly in the type of stimuli used: Experiment 1 concerned dot patterns, Experiment 2 polygons, Experiment 3 filled contour shapes, and Experiment 4 parentheses (see Figures 2a, 2b, 2c, and 2d, respectively). Experiment 1 further differed in that it included a control experiment, to check whether the tachistoscopic and visual search tasks were indeed comparable.

Dot patterns have been most popular in symmetry research, but studies have shown that pattern type may have some effects on symmetry detection. For instance, Wagemans (1993; see, also, Wagemans, Van Gool, \& d'Ydewalle, 1990) showed that closed contour patterns led to better performance than did dot patterns, for both frontoparallel and depth-skewed symmetries. Closed contour polygons were also used by Palmer and Hemenway (1978), who proposed a dual-process theory of symmetry detection. According to this theory, a fast, parallel global analysis is conducted on the pattern first, followed by a slow, detailed point-by-point matching process across the axis found in the first stage. This bears some attractive similarities to the classic dual-stage attention model outlined above. In Experiment 2, we investigated, with similar polygons, whether such a first parallel analysis generalizes to the multiple pattern level.

The use of solid block contour shapes (Experiment 3) was inspired by Baylis and Driver (1994). Baylis and Driver (1994, 1995; see also Bertamini, Friedenberg, \& Kubovy, 1997) argued that the (mirror) symmetry of a solid shape is so effortlessly perceived because it is concomitant on the preattentive decomposition of that same object into parts. That is, a symmetric object is characterized by a perfect correspondence of convexities and concavities across its axis: A convexity on the one side matches a convexity on the other, resulting in an unambiguous part description, because parts are usually convex (Hoffman \& Richards, 1984). In the present study, we investigated whether similar solid objects also yield parallel symmetry detection across multiple patterns. Experiment 4 concerned parentheses and will be treated after the discussion of Experiments 1-3.
In all the experiments, we restricted ourselves to symmetry about a vertical axis, because, of all mirror symmetries, it seems to be the most salient one (Barlow \& Reeves, 1979; Rock \& Leaman, 1963; Royer, 1981; Wagemans, Van Gool, \& d'Ydewalle, 1992). We assumed that, if there were no emergent feature effect for vertical symmetry, we would also fail to find one for symmetries at any other orientation.

\section{GENERAL METHOD}

\section{Subjects}

Forty-eight undergraduate and postgraduate students participated for money or course credits. Ages ranged from 19 to 35 . All had (corrected-to-normal) vision. Twelve subjects were assigned to Experiments 1A, 2, and 4; 6 to Experiments $1 \mathrm{~B}$ and 3.

\section{Design, Tachistoscopic Task}

In the tachistoscopic task, single patterns were presented for $120 \mathrm{msec}$, to preclude eye movement effects. The subjects' task was to classify the patterns as either symmetric or asymmetric. This task served three purposes. The main aim was to test whether the patterns we chose yielded performances in accordance with Julesz's definition of preattentive perception. The patterns were presented off fixation at unpredictable positions, and the second function of this task was to see whether symmetry was detectable at this particular eccentricity, thereby serving as a control for the visual search task, in which the patterns were presented at exactly the same locations. The third purpose of this task was to familiarize the subject with the type of pattern, giving him or her extensive practice in symmetry detection before the search task began. If the subjects failed at Experiment $1 \mathrm{~A}$ beforehand, the data of Experiment 1B would not be of much use, because serial search results could well be due to the failure to detect symmetry at the particular eccentricity in the first place (i.e., because of acuity problems), rather than being due to selective attention effects. We adopted a criterion of $90 \%$ correct, for the rest of the particular subject's data to be accepted.

\section{Visual Search Task}

The same subjects subsequently completed a visual search task. One to four items were displayed at the same eccentricity as in the tachistoscopic task, but now until a response was made. On half the number of trials, one of the distractors was replaced with a target, and the subject's task was to decide whether it was present or not. In the symmetry condition, the target pattern was a symmetric pattern among asymmetric distractors. In the asymmetry condition, the target pattern was an asymmetric pattern among symmetric patterns. We included this condition because search asymmetries have been used in the past as a diagnostic for preattentive feature detection (Treisman \& Gormican, 1988; Treisman \& Souther, 1985). A target specified by the presence of a particular feature may yield parallel search characteristics, whereas a target defined by the absence of that same feature may yield serial search results. For instance, it is easier to find a $Q$ among $O$ s than vice versa, assigning the status of a feature to the extra line segment of the $\mathrm{Q}$. In the control condition, the target was a symmetric pattern with the axis of symmetry drawn in (as a vertical line segment). This condition was somewhat trivial, in the sense that the line segment was very salient and would almost certainly yield flat slopes. This was necessary to provide a baseline. It also served to see whether there were any external factors preventing parallel search. In addition, this condition allowed for a possible comparison with the symmetry condition concerning the characteristics of the possible emergent feature. A candidate for an emergent property could be the symmetry axis. 
Studies have shown that the axis of symmetry is very salient, that its orientation can be determined very precisely, and that it plays an important role in determining a major object axis (see, e.g., Biederman, 1987; Locher \& Nodine, 1987; Quinlan \& Humphreys, 1993; Wenderoth, 1995). Perhaps, then, the axis would be comparable to a virtual line segment.

\section{Procedure}

In the tachistoscopic task, each trial started with a fixation cross. The subjects were instructed to focus on the cross and to try not to move their eyes during the entire trial. After $800 \mathrm{msec}$, a pattern was presented for $120 \mathrm{msec}$ on a random location on a virtual circle, while the fixation cross stayed on. Involuntary eye movements would thus be too late (Fischer, 1986). The subject's task was to decide as quickly and accurately as possible whether the pattern was vertically symmetric or not, by pressing a corresponding button on a buttonbox. After 1,200 msec, a new trial started. RTs were recorded in milliseconds, from stimulus onset. In case the response did not occur within the range of 200-5,000 msec after stimulus onset or was incorrect, a beep was sounded, and the particular trial was repeated by intermingling it with the remaining trials. Each subject first completed a practice block of 150 randomly mixed trials. During the first 50 trials, the presentation time gradually decreased to $120 \mathrm{msec}$. After the practice block, an identical experimental block followed. The first 50 trials were not included in the analyses; thus, on average, 50 symmetric and 50 asymmetric trials remained. The subjects were requested to try to obtain an overall level of accuracy of at least $90 \%$. Halfway and at the end of each block, there was a break, at which the (interim) score and mean RT were presented on screen.

In the visual search task, one to four patterns were presented. They stayed on until a response was made, as did the fixation cross.
The subject's task was to decide as quickly and accurately as possible whether a target pattern was present or absent, by pressing one of two buttons accordingly. Following the response, the screen went blank, and, after $1,200 \mathrm{msec}$, a new trial started. The target was present on half the number of trials. False trials were repeated. As in the tachistoscopic task, the subjects were requested to try to maintain an overall level of accuracy of at least $90 \%$ correct. In the symmetry condition, the target was a symmetric pattern, whereas the distractors were random patterns. In the asymmetry condition, it was vice versa. In the control condition, the subjects were instructed to search for the symmetric pattern (now containing a line segment). The three main conditions were blocked and completely counterbalanced between subjects. The different display size and target present/absent conditions were randomly mixed within subjects. Each cell contained 20 correct trials; thus, there were 160 correct trials per block. Before each block, the subjects completed a practice block of 32 representative trials. The assignment of the buttons to positive (target symmetric or target present) and negative (target asymmetric or target absent) responses stayed the same across all conditions. In the case of 12 subjects, we also balanced for hand dominance. The subjects were encouraged to have a break whenever they needed one. The experiment was run in a dimly lit, quiet experiment room and took about $1 \mathrm{~h}$ in total.

\section{EXPERIMENT 1A}

Experiment 1 consisted of two parts. In Experiment $1 \mathrm{~A}$, the two operationalizations of preattentive perception were directly compared. That is, the limited viewing time single pattern tachistoscopic task was contrasted with the unlimited viewing time multiple pattern visual

\section{(a)}
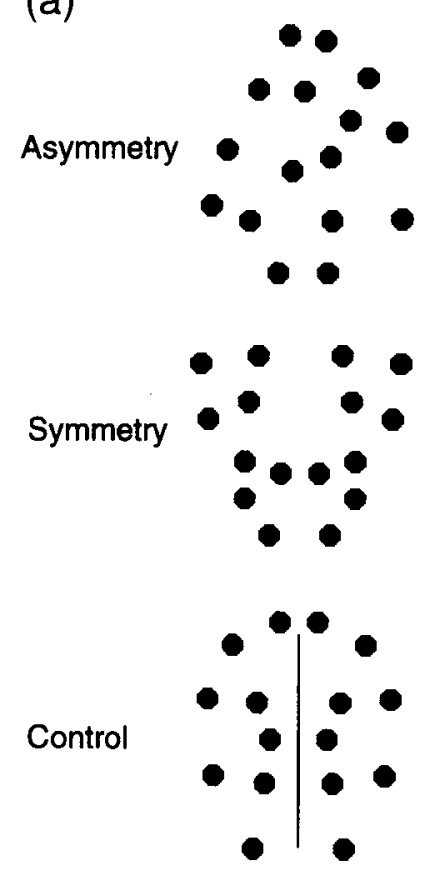

Experiment 1
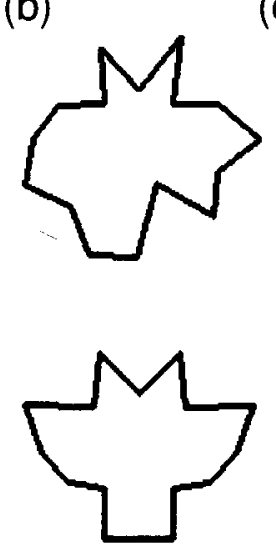

(b)

(c)

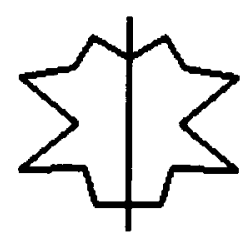

Experiment 2
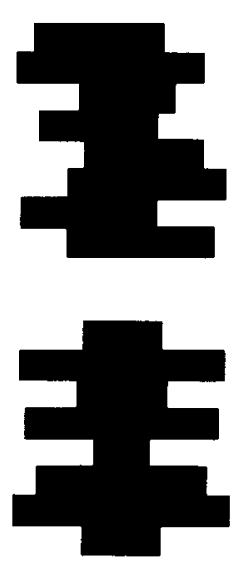

(d)
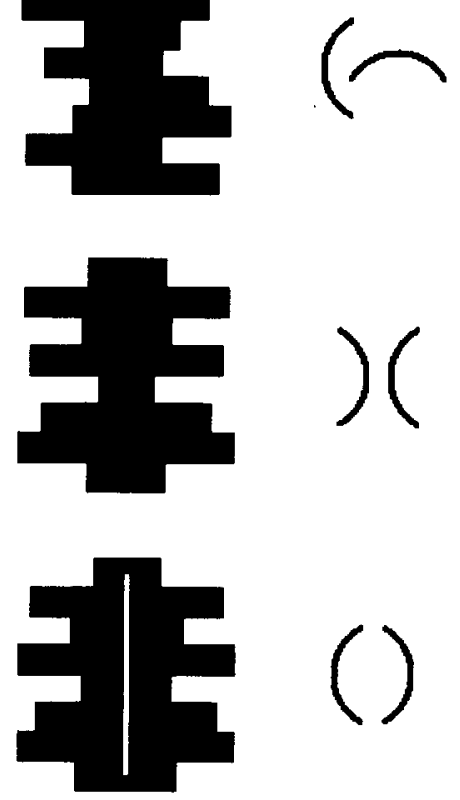

Experiment 3 Experiment 4

Figure 2. Examples of the stimuli used in Experiments 1-4. In the symmetry condition, targets were symmetric, distractors asymmetric. In the asymmetry condition, vice versa. In the control condition, the symmetric target contained a line segment, except in Experiment 4, in which the target was formed by two closing parentheses (closure condition). 


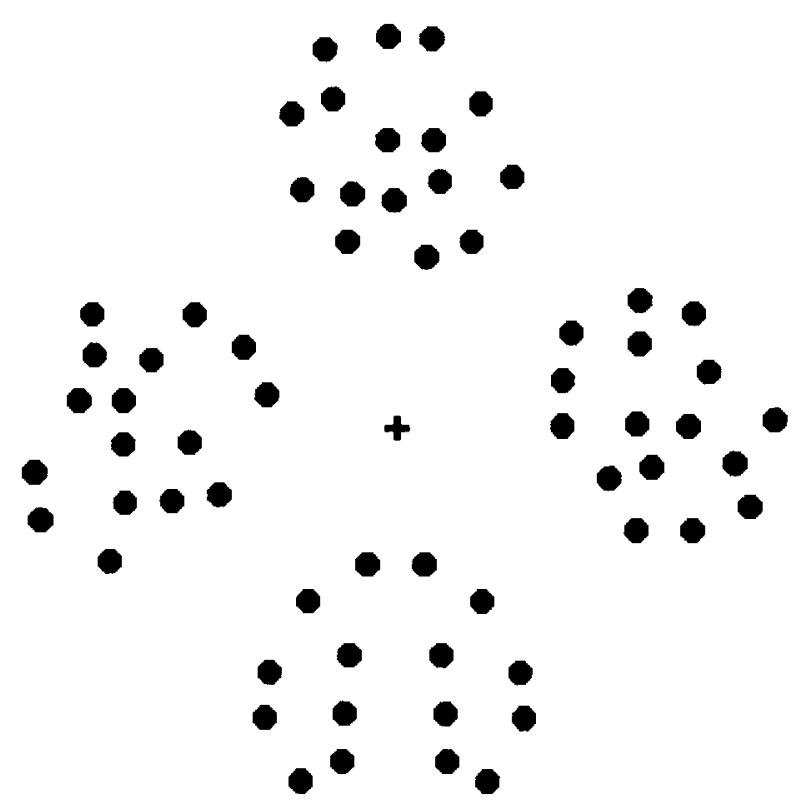

Figure 3. Example of a search display from the symmetry condition of Experiment 1 (display size 4, target present).

search task. Experiment $1 \mathrm{~B}$ was added as a control experiment, designed to check whether the difference in viewing time made the two tasks incomparable.

\section{Method}

A Turbo Pascal 7.0 program presented the instructions, generated the patterns, and recorded responses. Stimuli were presented in $\mathrm{Su}-$ perVGA $(1,024 \times 768)$ mode on a Philips Brilliance $15 \mathrm{~A}$ monitor, viewed from a distance of approximately $114 \mathrm{~cm}$. Each pattern consisted of 16 black dots (diameter approximately $0.13^{\circ}$ ) placed ran- domly within certain constraints (see Figure 2). In case of a symmetric pattern, 8 dots were reflected about a vertical axis. The background was light gray, yielding virtually no afterglow. The following limits applied: The interdot distance was at least $0.25^{\circ}$, and all the dots fell within a virtual circle with a diameter of $1.7^{\circ}$. This ensured that each pattern was reasonably homogeneous. Each pattern midpoint in its turn fell on the rim of a virtual circle with diameter $3.0^{\circ}$ around the fixation point, which was a blue cross. The total display area thus comprised a virtual disk with diameter $4.7^{\circ}$. For the visual search task, the following also holds: In case of display size two, the patterns were placed on the terminators of a virtual randomly rotated line through the fixation point. In case of display sizes three or four, the patterns were placed on the vertices of a randomly oriented virtual equilateral triangle or square, respectively. In the visual search control condition, the target contained a $1.5^{\circ}$ long black line segment positioned at its axis of symmetry. An example of a visual search display from the symmetry condition is shown in Figure 3.

\section{Results and Discussion}

For each task, we analyzed RTs and accuracy. However, for the tachistoscopic task, accuracy was the most important criterion. If a subject did not reach an overall level of at least $90 \%$ correct, his/her data were rejected, and we ran another subject. The same procedure was applied to the visual search task, just as when $35 \%$ or more errors were made in one of its cells. In total, we substituted 4 subjects, 2 of which failed at the tachistoscopic task. For each subject cell, we calculated mean correct RTs, excluding data points that fell above or below three standard deviations from the mean. This meant a loss of $1.1 \%$ of the data, though rarely more than one data point per cell per subject. Descriptive error and RT statistics are shown in Tables 1 and 2, and search functions are plotted in Figure 4.

Tachistoscopic task. The mean RTs were $562 \mathrm{msec}$ for asymmetric patterns and $536 \mathrm{msec}$ for symmetric pat-

Table 1

Error Percentages for Experiments 1-3 (Dot Patterns, Polygons, and Block Shapes, Respectively)

\begin{tabular}{|c|c|c|c|c|c|c|c|c|}
\hline \multirow[b]{2}{*}{ Display Size } & \multicolumn{2}{|c|}{ Tachistoscopic } & \multicolumn{2}{|c|}{ Symmetry } & \multicolumn{2}{|c|}{ Asymmetry } & \multicolumn{2}{|c|}{ Control } \\
\hline & Asym & Sym & Absent & Present & Absent & Present & Absent & Present \\
\hline \multicolumn{9}{|c|}{ Experiment 1A } \\
\hline 1 & 6.5 & 6.8 & 1.2 & 2.3 & 5.0 & 3.3 & 1.2 & 1.6 \\
\hline 2 & & & 1.6 & 7.2 & 3.8 & 7.4 & 0.8 & 2.3 \\
\hline 3 & & & 1.2 & 8.6 & 6.3 & 10.7 & 0.4 & 3.5 \\
\hline 4 & & & 5.3 & 19.5 & 4.8 & 17.3 & 0.4 & 3.2 \\
\hline \multicolumn{9}{|c|}{ Experiment IB } \\
\hline 1 & & & 5.8 & 7.5 & 17.5 & 10.8 & 2.5 & 5.8 \\
\hline 2 & & & 8.3 & 19.2 & 20.8 & 30.0 & 3.3 & 5.0 \\
\hline 3 & & & 13.3 & 25.0 & 30.0 & 32.5 & 2.5 & 6.6 \\
\hline 4 & & & 19.2 & 39.2 & 20.0 & 49.2 & 1.7 & 2.5 \\
\hline \multicolumn{9}{|c|}{ Experiment 2} \\
\hline 1 & 6.8 & 5.8 & 4.3 & 0.8 & 7.1 & 8.4 & 2.7 & 3.5 \\
\hline 2 & & & 3.1 & 8.7 & 6.5 & 9.5 & 2.3 & 4.7 \\
\hline 3 & & & 3.4 & 7.2 & 3.8 & 8.7 & 0.4 & 3.5 \\
\hline 4 & & & 4.2 & 10.5 & 4.7 & 13.4 & 1.6 & 4.8 \\
\hline \multicolumn{9}{|c|}{ Experiment 3} \\
\hline 1 & 3.4 & 3.2 & 1.6 & 0.8 & 2.3 & 5.3 & 0.0 & 0.8 \\
\hline 2 & & & 2.3 & 7.4 & 3.1 & 3.1 & 1.6 & 2.4 \\
\hline 3 & & & 1.5 & 11.0 & 2.3 & 6.2 & 0.8 & 2.4 \\
\hline 4 & & & 3.1 & 19.4 & 3.8 & 9.3 & 0.0 & 0.8 \\
\hline
\end{tabular}


Table 2

Search Function Characteristics for Experiments 1-3 (Dot Patterns, Polygons, and Block Shapes; Slopes and Intercepts in Milliseconds)

\begin{tabular}{|c|c|c|c|c|c|c|}
\hline & \multicolumn{2}{|c|}{ Symmetry } & \multicolumn{2}{|c|}{ Asymmetry } & \multicolumn{2}{|c|}{ Control } \\
\hline & Absent & Present & Absent & Present & Absent & Present \\
\hline \multicolumn{7}{|c|}{ Experiment $1 \mathrm{~A}$} \\
\hline Slope & 171.6 & 116.5 & 181.0 & 105.1 & 1.0 & 0.3 \\
\hline Intercept & 452.0 & 439.4 & 482.5 & 563.9 & 450.4 & 414.8 \\
\hline$\%$ Linearity & 99.5 & 99.4 & 98.0 & 93.5 & 1.9 & 65.6 \\
\hline \multicolumn{7}{|c|}{ Experiment $1 \mathrm{~B}$} \\
\hline Slope & 42.1 & 34.3 & 43.1 & 75.6 & -3.0 & -2.2 \\
\hline Intercept & 578.0 & 552.5 & 730.1 & 586.8 & 480.8 & 446.0 \\
\hline$\%$ Linearity & 96.3 & 79.5 & 91.4 & 95.8 & 35.7 & 0.1 \\
\hline \multicolumn{7}{|c|}{ Experiment 2} \\
\hline Slope & 142.5 & 87.4 & 88.5 & 67.1 & -3.3 & 14.8 \\
\hline Intercept & 438.3 & 439.2 & 534.1 & 541.9 & 462.7 & 405.4 \\
\hline$\%$ Linearity & 98.2 & 99.1 & 93.2 & 94.2 & 64.2 & 90.8 \\
\hline \multicolumn{7}{|c|}{ Experiment 3} \\
\hline Slope & 171.8 & 139.1 & 139.6 & 78.5 & 0.8 & 6.3 \\
\hline Intercept & 454.2 & 444.5 & 458.1 & 518.2 & 452.1 & 427.8 \\
\hline$\%$ Linearity & 99.6 & 99.8 & 99.5 & 97.3 & 3.0 & 81.6 \\
\hline
\end{tabular}

terns and differed significantly [two-tailed paired $t(11)=$ $2.988, p<.05]$. Mean error percentages did not differ significantly $[t(11)=-0.143, p=.889]$. Overall accuracy was $93.3 \%$.

Visual search task, RTs. All the subjects showed a similar pattern, and there seemed not to be much effect of order of conditions. An overall three-way repeated measures analysis of variance (ANOVA) on mean correct RTs, with condition (symmetry/asymmetry/control), target (absence/presence), and display size $(1-4)$ as factors, yielded significant effects for all main effects and all interactions $(p s<.001)$. More meaningful separate ANOVAs were conducted in order to compare the different conditions.

Symmetry versus control. A three-way ANOVA revealed significant main effects for condition $[F(1,11)=$ $\left.141.41, M S_{\mathrm{e}}=46,879.9, p<.001\right]$, target $[F(1,11)=$ $\left.49.13, M S_{\mathrm{e}}=8,593.8, p<.001\right]$, and display size $\left[F(1.25,13.78)=53.13, M S_{\mathrm{e}}=7,890.6, p<.001\right] .^{2}$ Inspection of Figure 4 shows that RTs were slower in the symmetry condition, were slower on absent trials, and increased with larger display sizes. However, target absence had more effect in the symmetry condition, resulting in a target $\times$ condition interaction $[F(1,11)=20.90$, $\left.M S_{\mathrm{e}}=7,340.9, p=.001\right]$. Most important, the display size effect was also mainly due to the symmetry condition [condition $\times$ display size: $F(1.27,13.98)=63.42$, $\left.M S_{\mathrm{e}}=6,526, p<.001\right]$, indicating a difference in search slopes. Furthermore, the target $\times$ display size interaction reached significance $\left[F(2.01,22.13)=7.75, M S_{\mathrm{e}}=\right.$ $2,110.8, p<.01]$. This reflects the fact that slopes were steeper on absent trials. The condition $\times$ target $\times$ display size interaction $\left[F(2.09,22.97)=6.12, M S_{\mathrm{e}}=\right.$ $2,713.0, p<.01]$ was also significant, and Figure 4 shows that this was mainly due to the target by display size interaction being more clear in the symmetry than in the control condition.

Symmetry versus asymmetry. RTs were generally slower in the asymmetry condition (mainly reflecting an increase in intercept), were slower for absent trials, and increased with display size $\left[F(1,11)=6.25, M S_{\mathrm{e}}=\right.$ $43,125.9, p<.05 ; F(1,11)=56.79, M S_{\mathrm{e}}=14,134.0$, $p<.001 ; F(1.40,15.37)=103.76, M S_{\mathrm{e}}=16,092.3, p<$ .001 , respectively]. Further, only the target $\times$ display size interaction reached significance $[F(2.27,24.93)=19.51$, $M S_{\mathrm{e}}=4,522, p<.001 ;$ all other interactions, $\left.p \mathrm{~s}>.1\right]$, as display size had a larger effect on absent trials. There was no reliable slope (display size $\times$ condition) difference.

Visual search task errors. The overall error percentage $(6.7 \%)$ was low. The pattern followed the RTs-that is, the number of errors was smallest in the control condition and about equal for the two other conditions. Errors increased with display size, but more so on present trials, on which, in general, more errors were made. This effect is common and reflects a deadline strategy: When the target has not been found within a certain time limit, search is terminated and absent is responded, resulting in a bias toward absent trials. There were no signs of a speed/accuracy tradeoff.

Between tasks comparison. An RT comparison between the tachistoscopic task and display size 1 of the symmetry search condition did not reveal any difference for positive (symmetric vs. present) trials [536 vs. $548 \mathrm{msec}$, respectively; $t(11)=-0.848, p=.415]$ but did so for negative (asymmetric vs. absent) trials (562 vs. $612 \mathrm{msec}$, respectively; $t(11)=-4.096, p<.01]$. A two-way ANOVA on the error data, with task and target as factors, yielded a significant effect of task $[F(1,11)=$ $\left.56.727, M S_{\mathrm{e}}=5.9, p<.001\right]$. The target effect and the target $\times$ task interaction did not reach significance $(p s>$ 
Tachistoscopic

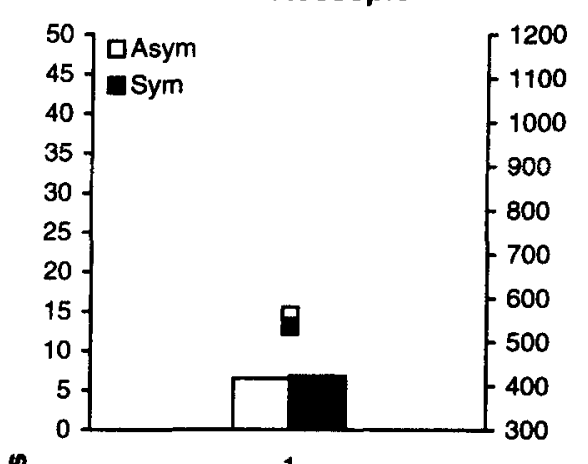

논

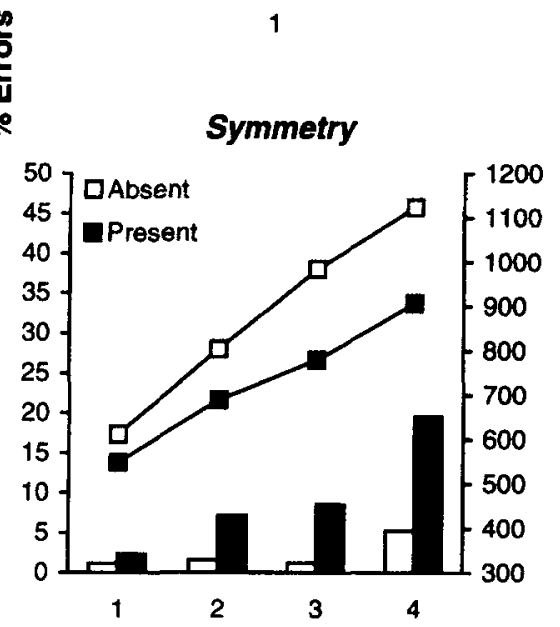

\section{Control}

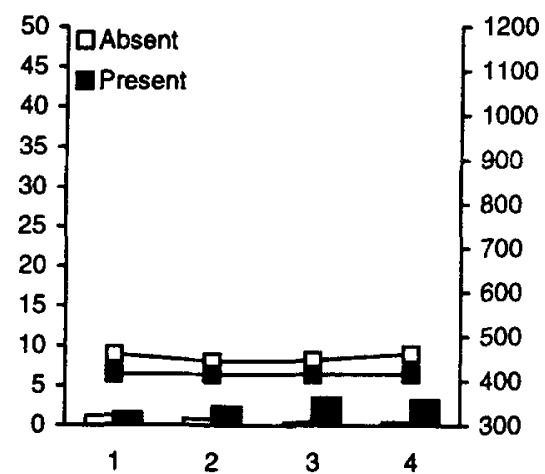

Asymmetry

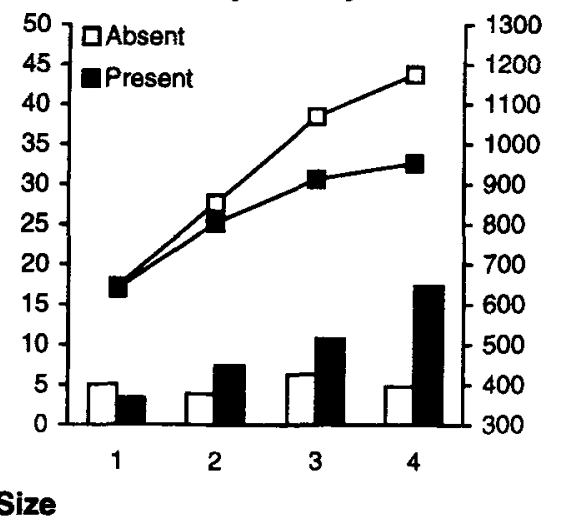

Figure 4. Results from the tachistoscopic and visual search tasks of Experiment 1A. The columns correspond to error percentages, the small squares to $R T s$.

.75). Thus, reliably more errors were made in the tachistoscopic task, but RTs were faster, at least on absent trials. The between-task comparisons were more or less the same for all subsequent experiments and will not be mentioned further.

The results of Experiment $1 \mathrm{~A}$ show a clear dissociation between performances with single and multiple pattern presentations, respectively. Whereas single patterns could easily be judged on their symmetry, multiple patterns could not: Larger display sizes led to longer RTs and more errors. We will discuss these results more thoroughly in the Discussion section after Experiment 3. First, however, we need to show that the tachistoscopic and visual search tasks are indeed comparable in the way we did compare them. Note that, besides the number of patterns in the display, the two tasks differed in stimulus presentation times. In the visual search task, the displays were presented until response, and this may have encouraged the subjects to adopt a serial search strategy, even more because they were asked to keep a high level of accuracy. The brief flashing of the single patterns in the tachistoscopic task, on the other hand, may have stimulated the subjects to respond more quickly (and to be a bit more error prone; see the between-tasks comparison).
In Experin.ent 1B, we therefore repeated the visual search task, but now with short presentation times $(120 \mathrm{msec})$. This should encourage the subjects to respond more quickly. However, if the search for symmetry was serial, not because the task allowed for it, but because symmetry is just hard to find, this should be reflected in an increase in the number of errors.

\section{EXPERIMENT 1B}

\section{Method}

The setup was identical to that in the visual search task of Experiment $1 \mathrm{~A}$. The only differences concerned the stimulus presentation time (now $120 \mathrm{msec}$ ) and the amount of practice. We made the number of practice trials for each condition (symmetry, asymmetry, and control) equal to roughly the level of the tachistoscopic task of Experiment $1 \mathrm{~A}$ - that is, 160 trials. During the practice block, presentation times gradually decreased from unlimited to $120 \mathrm{msec}$.

\section{Results and discussion}

RTs and errors were analyzed in the same way as in Experiment $1 \mathrm{~A}$ and are shown in Tables 1 and 2 and Figure 5. Clipping RTs outside three standard deviations from the mean resulted in a loss of $1.1 \%$ of the total number of data points. 
은

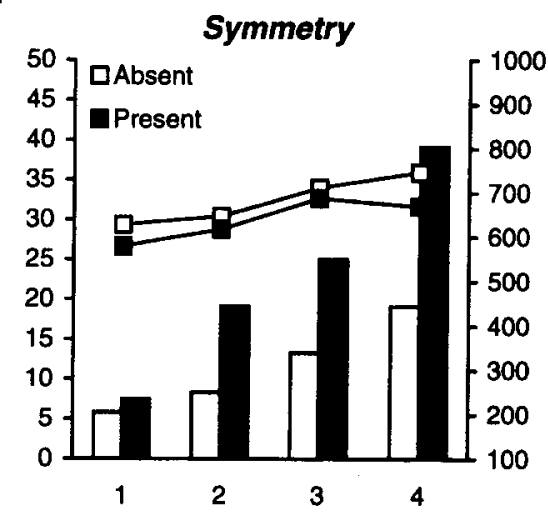

Control

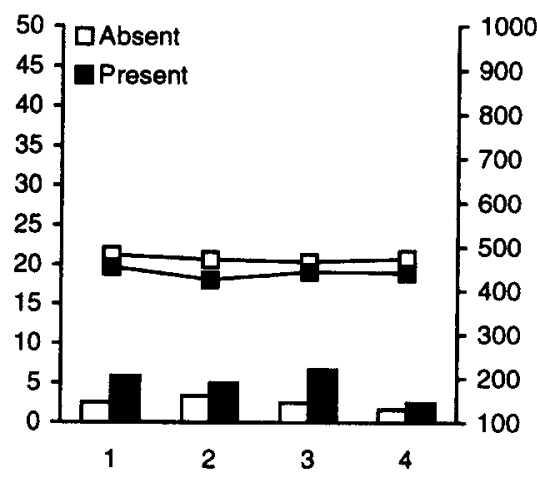

Asymmetry

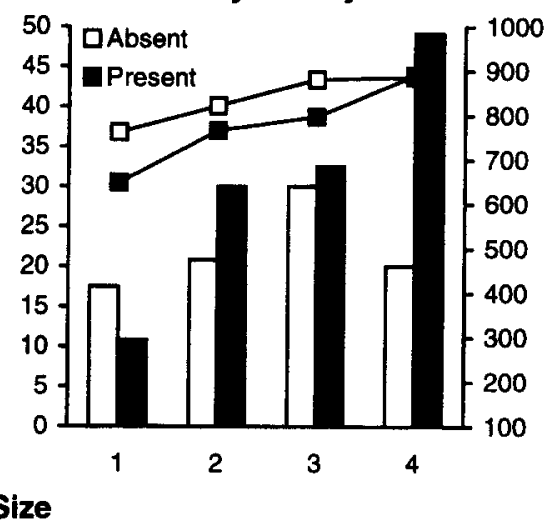

Figure 5. Results from the limited viewing time visual search tasks of Experiment 1B. The columns correspond to error percentages, the small squares to RTs.

Symmetry versus control. RTs were faster in the control condition $\left[F(1,5)=198.1, M S_{\mathrm{e}}=5,037.6, p<.001\right]$, faster on present trials $\left[F(1,5)=12.95, M S_{\mathrm{e}}=2,788.6, p<.05\right]$, and, overall, faster at smaller display sizes $[F(2.54,12.68)=$ $\left.9.77, M S_{\mathrm{e}}=1,461.6, p=.001\right]$. Further, search slopes were reliably steeper in the symmetry condition $[F(2.09,10.45)$ $\left.=16.04, M S_{\mathrm{e}}=1,121.8, p=.001\right]$. No other interactions reached significance.

Symmetry versus asymmetry. RTs were, overall, faster in the symmetry condition $\left[F(1,5)=26.74, M S_{\mathrm{e}}=\right.$ $19,132.1, p<.01]$ and were faster on present trials $[F(1,5)$ $\left.=45.32, M S_{\mathrm{e}}=1,510.9, p=.001\right]$. RTs increased with increasing display size $\left[F(1.52,7.60)=37.66, M S_{\mathrm{e}}=\right.$ $2,576.4, p<.001]$. There were no other reliable differences between the two conditions. All interactions failed to reach significance.

Errors. As can be seen from Figure 5, the error pattern again closely followed the RTs. Because limiting the viewing time had a large effect on the number of errors, we report the results more fully. In comparing the symmetry and asymmetry conditions, we found that generally more errors were made in the asymmetry condition, as well as on present trials and on larger display sizes
$\left[F(1,5)=13.03, M S_{\mathrm{e}}=154.8, p<.05 ; F(1,5)=11.85\right.$, $M S_{\mathrm{e}}=194.17, p<.05 ; F(1.89,9.45)=60.43, M S_{\mathrm{e}}=$ $32.78, p<.001$, respectively]. Of the interactions, only the target $\times$ display size was reliable $[F(1.38,6.90)=$ $\left.5.29, M S_{\mathrm{e}}=142.64, p<.05\right]$, reflecting the relatively larger effect display size had on present trials. Comparing the symmetry with the control condition yielded significant effects of condition $\left[F(1,5)=22.90, M S_{\mathrm{e}}=\right.$ $189.22, p<.01]$, target $\left[F(1,5)=19.26, M S_{\mathrm{e}}=57.14\right.$, $p<.01]$, and display size $\left[F(1.57,7.85)=8.40, M S_{\mathrm{e}}=\right.$ $53.66, p<.05]$. Most important, the condition $\times$ display size interaction was also very reliable $[F(2.02,10.10)=$ $\left.17.34, M S_{\mathrm{e}}=37.14, p=.001\right]$, reflecting the difference in error slopes. No other interactions were significant.

The findings are again clear. In the control condition, both RTs and the number of errors stayed fairly low. Search slopes were flat, indicating parallel detection of the line target. In contrast, the results from the symmetry and asymmetry conditions strongly indicate serial performance. In both conditions, the error percentage increased rapidly (about $95 \%$ linearity) with display size. Performance dropped at a rate of around $10 \%$ per extra item on present trials, down to only $50 \%-60 \%$ correct at 
display size 4. This is close to guessing. Relative to Experiment $1 \mathrm{~A}$, overall RTs were indeed faster, and search slopes were less steep. This suggests that short presentation times do provoke subjects to speed up their responses to some extent (though note that slopes are still fairly steep) but that this gain in RTs is accompanied by a severe loss in accuracy at larger display sizes. We are, therefore, confident that the standard visual search task and the tachistoscopic task are comparable in the way we compared them in Experiment 1A. Serial performance occurs because of the presence of multiple patterns, not because of unlimited viewing time. In the next experiments, we applied the same comparison to different types of stimuli, to see whether the results generalize to other patterns.

\section{EXPERIMENT 2}

\section{Method}

The display area and stimulus measures were the same as those in Experiment 1. Random polygons (Figure 2) were constructed by connecting the endpoints of 16 equally spaced virtual radii (placed every $22.5^{\circ}$, starting from the vertical) of randomly different lengths. Lengths varied between $0.3^{\circ}$ and $0.85^{\circ}$, with the constraint that each radius differed at least $0.09^{\circ}$ from its neighbors. Symmetrical polygons were constructed in the same way, by reflecting eight line segments across a vertical axis. The line segments were 3 pixels $\left(0.4^{\circ}\right)$ thick and were drawn in black on a light gray background.

\section{Results}

The data were treated in the same way as in Experiment 1 . One subject was replaced, because of more than $40 \%$ errors in one of the cells of the search task. Moreover, $1.2 \%$ of the data points were lost because of the trimming procedure. Descriptive results are shown in Tables 1 and 2 and in Figure 6.

Tachistoscopic task. The mean RTs were $561 \mathrm{msec}$ for asymmetric patterns and $523 \mathrm{msec}$ for symmetric patterns and differed significantly $[t(11)=4.504, p=.001]$. The mean error percentages for asymmetric and symmetric patterns did not $[t(11)=0.893, p=.391]$. The overall level of accuracy was $93.7 \%$.

Visual search task, symmetry versus control. As in Experiment 1, RTs were, overall, longer in the symmetry condition $\left[F(1,11)=147.28, M S_{\mathrm{e}}=25,132.65, p<\right.$ $.001]$, were longer on absent trials $[F(1,11)=59.49$, $\left.M S_{\mathrm{e}}=4,476.82, p<.001\right]$, and increased with larger display sizes $\left[F(2.12,23.32)=117.94, M S_{\mathrm{e}}=2,495.82\right.$, $p<.001]$. Target presence/absence had significantly more effect in the symmetry condition than in the control condition $\left[F(1,11)=57.80, M S_{\mathrm{e}}=3,231.97, p<.001\right]$,

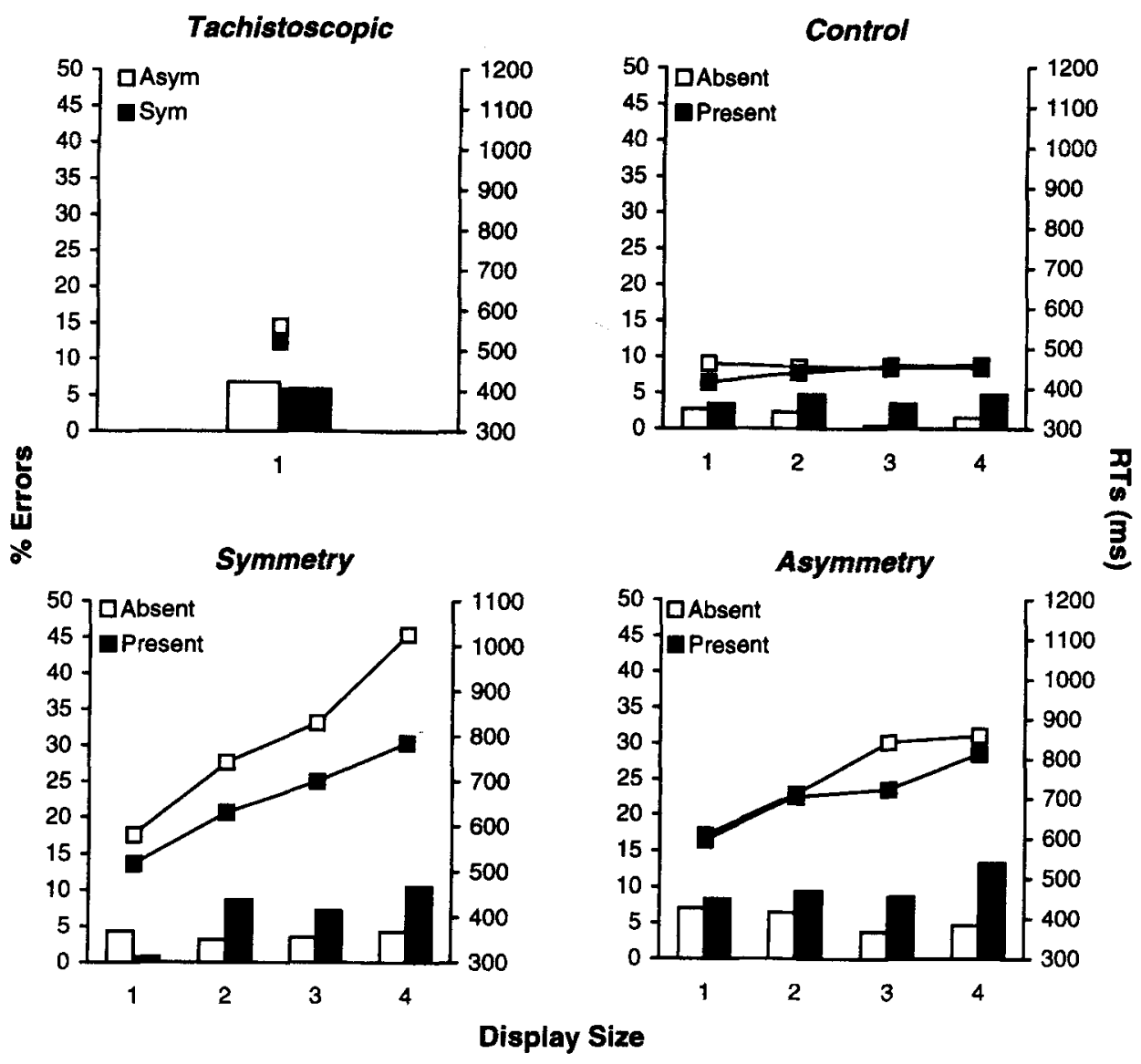

Figure 6. Results from the tachistoscopic and visual search tasks of Experiment 2. The columns correspond to error percentages, the small squares to $R T s$. 
as had display size $\left[F(2.26,24.87)=92.57, M S_{\mathrm{e}}=\right.$ $2,613.95, p<.001]$. Thus, search slopes differed reliably. Display size had more effect on target absence than on target presence $\left[F(2.66,29.25)=10.02, M S_{\mathrm{e}}=\right.$ $995.68, p<.001]$, but mainly so in the symmetry condition $\left[F(2.28,25.11)=35.30, M S_{\mathrm{e}}=786.61, p<.001\right]$.

Symmetry versus asymmetry. Absent trials were overall slower than present trials, and RTs increased with display size $\left[F(1,11)=70.62, M S_{\mathrm{e}}=5,667.46, p<.001\right.$, and $F(1.78,19.63)=127.64, M S_{\mathrm{e}}=5,869.23, p<.001$, respectively]. Display size generally had more effect on absent trials $\left[F(2.72,29.91)=10.43, M S_{\mathrm{e}}=2,951.78\right.$, $p<.001]$. In contrast to Experiment 1, RTs were not overall slower in the asymmetry condition $[F(1,11)=0.093$, $\left.M S_{\mathrm{e}}=20,372.0, p=.767\right]$. Further differences concerned some interactions. As can be seen from Figure 6 and Table 2, target absence seems to have had more effect in the symmetry condition than in the asymmetry condition [condition $\times$ target: $F(1,11)=25.59, M S_{\mathrm{e}}=3,894.5$, $p<.001]$. Also, the condition $\times$ display size interaction was reliable $\left[F(2.19,24.05)=13.96, M S_{\mathrm{e}}=2,406.1, p<\right.$ $.001]$, indicating a difference in search slopes. Moreover, the condition $\times$ target $\times$ display size interaction was significant $\left[F(2.44,26.89)=6.23, M S_{\mathrm{e}}=3,094.0, p<.01\right]$.
Therefore, we conducted separate two-way analyses on present and absent trials and found a significant condition $X$ display size interaction (i.e., slope difference) for absent trials $\left[F(2.14,23.57)=15.3, M S_{\mathrm{e}}=3,092.1, p<.001\right]$ but not for present trials $\left[F(2.36,25.96)=2.20, M S_{\mathrm{e}}=\right.$ $2,354.0, p=.124]$.

The discussion of the results is deferred to the Discussion section after Experiment 3.

\section{EXPERIMENT 3}

\section{Method}

The stimuli were somewhat vertically elongated solid shapes, with two jagged sides consisting of eight contour steps each. The whole resembled a sloppy pile of eight books (see Figure 2). The shapes were drawn in black on a gray background and measured $1.6^{\circ} \times 0.91^{\circ}$ on average, with a minimum width of $0.37^{\circ}$. The symmetric shapes were constructed by randomly choosing 1 out of 14 begin-points on the left, each $0.04^{\circ}$ apart, for each of the eight contour steps. A $0.2^{\circ}$ thick solid bar was then drawn from this beginpoint to its point of reflection across the midline. Neighboring steps always differed by at least $0.12^{\circ}$ in length. In the case of random shapes, the right contour steps also were chosen at random, with the additional constraint that their lengths differed by at least $0.16^{\circ}$ from their partners on the opposite side. The overall display organization and measures were the same as those in the former experiments.
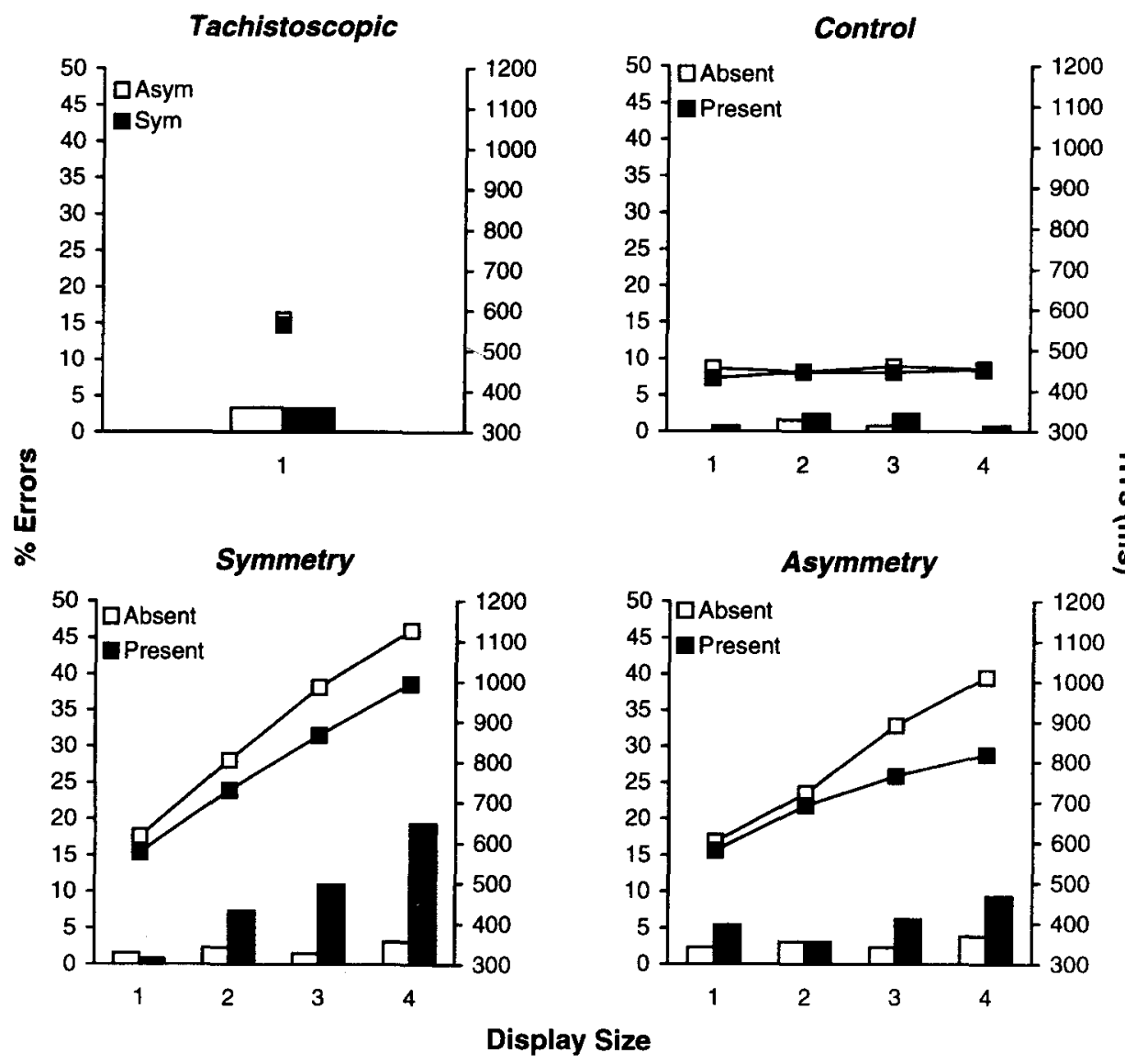

Figure 7. Results from the tachistoscopic and visual search tasks of Experiment 3. The columns correspond to error percentages, the small squares to $R T s$. 


\section{Results}

Figure 7 and Tables 1 and 2 show the main results. Mean correct RTs in the tachistoscopic task of Experiment $3 \mathrm{~A}$ were $566 \mathrm{msec}$ for symmetric patterns and $578 \mathrm{msec}$ for asymmetric patterns and did not differ reliably $[t(5)=0.914, p=.403]$. The overall percentage correct was $96.7 \%$, with no difference between symmetric and asymmetric patterns $[t(5)=0.207, p=.844]$.

Visual search, symmetry versus control. RTs increased with display size, were slower in the symmetry condition, and were slower on absent trials $[F(1.44,7.21)$ $=99.89, p<.001 ; F(1,5)=141.03, M S_{\mathrm{e}}=25,768, p<$ $.001 ; F(1,5)=18.78, M S_{\mathrm{e}}=3,318.12, p<.01$, respectively]. Display size and target absence/presence had more effect in the symmetry condition, as indicated by the slope differences in Figure $7\left[F(1,5)=15.85, M S_{\mathrm{e}}=\right.$ $2,479.07, p<.05 ; F(1.41,7.07)=99.25, p<.001]$. The target $\times$ display size and the three-way condition $\times$ target $X$ display size interactions failed to reach significance $\left[F(1.69,8.44)=1.08, M S_{\mathrm{e}}=2,002.7, p=.369\right.$, and $F(1.41,7.06)=2.015, M S_{\mathrm{e}}=1,887.7, p=.203$, respectively].

Symmetry versus asymmetry. The main effects of condition, target, and display size were significant $[F(1,5)$ $=15.31, M S_{\mathrm{e}}=9,356.05, p<.05 ; F(1,5)=10.94, M S_{\mathrm{e}}=$ $18,604.02, p<.05$; and $F(1.28,6.41)=111.6, M S_{\mathrm{e}}=$ $6,289.16, p<.001]$. Again, RTs were faster on present trials and on the smaller display sizes. In contrast to the former experiments, RTs were now, overall, faster in the asymmetry condition. The condition $\times$ display size interaction was also significant $[F(2.03,10.14)=10.28$, $\left.M S_{\mathrm{e}}=2,106.5, p<.01\right]$, reflecting the smaller slopes for the asymmetry condition on both present and absent trials. The condition $\times$ target interaction $[F(1,5)=0.00$, $\left.M S_{\mathrm{e}}=2,886.07, p=.954\right]$ and the three-way interaction $\left[F(1.55,7.76)=0.927, M S_{\mathrm{e}}=3,160.5, p=.411\right]$ were not reliable. The target $\times$ display size interaction just failed to reach significance $\left[F(1.16,5.79)=4.40, M S_{\mathrm{e}}=\right.$ $5,182.3, p=.08]$

\section{DISCUSSION OF EXPERIMENTS 1-3}

The data are quite clear and similar across all three experiments. The level of performance in the tachistoscopic tasks was high - that is, RTs were fast and the overall accuracy across tasks approached $95 \%$. Performance in the tachistoscopic task did not differ much from the single pattern presentations in the visual search task (display size 1). We are, therefore, confident that the patterns were well perceivable at the eccentricity we used-that is, the symmetry could be detected without the necessity for eye movements. This ensured that, if symmetry was perceived preattentively, it was done so before eye movements were made, thus providing a basis for the visual search tasks, in which eye movements were not explicitly controlled for.

The results from the tachistoscopic tasks are in line with Julesz's operationalization of effortless preattentive perception. In contrast, the results from the search tasks show a different picture. The control condition always yielded flat or close-to-flat slopes, indicating parallel detection. Of course, and rather trivially, the subjects made use of the extra line segment (as they reported themselves), although they were not instructed to do so. Most important, it shows that the experimental setup allowed for parallel search to occur. It also shows that subjects would use any extra information to find the target. For instance, one could have argued that not the symmetry relations themselves are emergent, but some related property, such as an axis, and that the subjects would thus look for the wrong information.

The most important task, the symmetry condition, yielded a highly serial search pattern in all experiments. This suggests that each pattern had to be selected in turn, in order for it to be evaluated on its symmetry. The asymmetry condition yielded a similar serial search pattern in all three experiments. Experiment 1B further showed that the serial character in both conditions was not due to unlimited viewing time. With limited viewing time, RTs still linearly increased, and the level of accuracy dropped considerably with display size (down to chance level).

In Experiment 1 A, there was no difference in search slopes between the symmetry and the asymmetry conditions. In other words, there was no search asymmetry. This further supports the idea that symmetry is not a basic visual primitive, because, if it were, its presence would be easier to detect than its absence (Treisman \& Gormican, 1988; Treisman \& Souther, 1985). However, in Experiments 2 and 3, a significant search asymmetry did emerge. Yet, note that this asymmetry goes in the opposite direction to that expected-that is, search slopes in the asymmetry condition were flatter than those in the symmetry condition, so it was generally easier to search for an asymmetry. This nonclassical search asymmetry can be explained by the general finding that symmetric (i.e., "good") shapes are more rapidly processed than asymmetric shapes (see, e.g., Palmer, 1983; Quinlan \& Humphreys, 1993; Sebrechts \& Garner, 1981). In the symmetry condition, on average, a few, more slowly processed asymmetric shapes have to be viewed first before the target is found, whereas, in the asymmetry condition, the symmetric distractors can be rejected more quickly.

In the last experiment, we did a final attempt to find an emergent symmetry. Perhaps the patterns we used so far were too complex, which may have caused some overload, even in the parallel system, resulting in serial performance (Townsend, 1972). This information overload may not have been expressed in the control condition, because the subjects were then probably looking for a totally different kind of information-namely, the line segment. We therefore decreased, and controlled for, complexity in Experiment 4. After all, emergent feature effects so far have only been found with very simple stimuli, consisting of two or three elements (Pomerantz \& Pristach, 1989; see Figure 1). 


\section{EXPERIMENT 4}

In Experiment 4, we made use of the parentheses stimuli first introduced by Pomerantz and Garner (1973) and shown in Figure 1. The experiment differed slightly from the ones reported above. In the tachistoscopic task, we presented either the symmetric configuration )( or one of eight asymmetric configurations, of which four are shown in Figure $1 \mathrm{~b}$ (the other four were the mirror images of these). The visual search task consisted of two main conditions. In the symmetry condition, a )( target was either present or absent among one to five asymmetric distractors. In the closure condition, the target was a () configuration among the same types of distractors. Pomerantz (Pomerantz \& Garner, 1973; Pomerantz \& Schwaitzberg, 1975 ) showed that, when the parentheses are placed close together, both these target configurations are treated wholistically, as single features, whereas the distractor configurations are not. The $)($ target contains a symmetry, the () target a symmetry and a near closure. Both characteristics have been mentioned as possible emergent features or preattentive perceptual binders (Pomerantz \& Garner, 1973; Pomerantz \& Pristach, 1989).

The closure condition now functioned as the control condition, since it was exactly as complex as the symmetry condition. If the symmetry condition yielded worse performance than the closure condition, complexity could not be the causal factor. We did not use the (( and )) configurations as distractors, since they may form distracting emergent features (Pomerantz \& Garner, 1973; Pomerantz \& Pristach, 1989).

\section{Method}

Stimuli. Each stimulus was formed by two parentheses (Figures $1 \mathrm{a}, 1 \mathrm{~b}$, and $2 \mathrm{~d}$ ), either both upright [in the case of a target, i.e., )( or ( )] or, at random, one upright and one lying horizontally (in the case of a distractor). The parentheses each comprised a $0.04^{\circ}$ thick arc of $120^{\circ}$, radius $0.37^{\circ}$, and were approximately $0.65^{\circ}$ tall $\times 0.15^{\circ}$ wide. The shortest distance between two parentheses was approximately $0.13^{\circ}$ in the case of a target and approximately $0.10^{\circ}$ in the case of a distractor. Pomerantz and Schwaitzberg (1975) showed that the closer together the parentheses are placed, the stronger the configurational effect. In our experiment, the parentheses were relatively even closer together than in Pomerantz and Schwaitzberg's original configuration. The overall display organization and measure were the same as those in the former experiments. In case of Display Size 5, the patterns were positioned on the vertices of a randomly rotated virtual pentagon.

Table 3

Error Percentages for Experiment 4 (Parentheses)

\begin{tabular}{|c|c|c|c|c|c|c|}
\hline \multirow[b]{2}{*}{ Display Size } & \multicolumn{2}{|c|}{ Tachistoscopic } & \multicolumn{2}{|c|}{ Symmetry } & \multicolumn{2}{|c|}{ Closure } \\
\hline & Asym & Sym & Absent & Present & Absent & Present \\
\hline 1 & 3.2 & 3.7 & 4.8 & 1.6 & 4.3 & 0.8 \\
\hline 2 & & & 2.9 & 2.0 & 3.1 & 2.2 \\
\hline 3 & & & 1.6 & 7.0 & 1.6 & 2.3 \\
\hline 4 & & & 2.2 & 9.0 & 1.6 & 3.0 \\
\hline 5 & & & 1.5 & 11.8 & 0.8 & 7.1 \\
\hline
\end{tabular}

Table 4

Search Function Characteristics for Experiment 4 (Parentheses; Slopes and Intercepts in Milliseconds)

\begin{tabular}{lccccc}
\hline & \multicolumn{2}{c}{ Symmetry } & & \multicolumn{2}{c}{ Closure } \\
\cline { 2 - 3 } \cline { 5 - 6 } & Absent & Present & & Absent & Present \\
Slope & 46.7 & 40.8 & & 4.9 & 12.2 \\
Intercept & 457.0 & 422.2 & & 465.1 & 406.4 \\
\% Linearity & 99.5 & 99.6 & & 31.2 & 79.0 \\
\hline
\end{tabular}

Design and Procedure. The design and procedure were basically the same as before. In the symmetry condition, the target was a ) ( configuration; in the closure condition, a () configuration. In both conditions, the instructions stressed symmetry as the important target feature - that is, closure or any other characteristic was never mentioned. Display size now varied from 1 to 5 , resulting in 200 trials for each block.

\section{Results and Discussion}

Mean correct RTs and error percentages were treated as before. The main findings are shown in Tables 3 and 4 and in Figure 8 . Owing to the trimming procedure, $0.9 \%$ of the data points were lost. In the tachistoscopic task, symmetric patterns yielded a mean RT of $459 \mathrm{msec}$, asymmetric patterns $470 \mathrm{msec}$ [no significant difference; $t(11)=$ $1.380, p=.195]$. The overall accuracy level was $96.5 \%$. Error percentages for symmetric versus asymmetric patterns did not differ either $[t(11)=0.462, p=.653]$.

Visual search, symmetry versus closure condition. RTs were faster in the closure condition $[F(1,11)=$ 97.98, $\left.M S_{\mathrm{e}}=7,347.9, p<.001\right]$, faster on present trials $\left[F(1,11)=14.83, M S_{\mathrm{e}}=8,074.4, p<.01\right]$, and faster with smaller display sizes $[F(1.55,17.10)=35.78$, $\left.M S_{\mathrm{e}}=2,320.8, p<.001\right]$. The condition $\times$ display size interaction was also significant $[F(1.93,21.26)=30.63$, $\left.M S_{\mathrm{e}}=1,234.8, p<.001\right]$, reflecting the fact that slopes were flatter in the closure condition. There was no target $\times$ display size interaction $\left[F(2.99,32.92)=1.16, M S_{\mathrm{e}}=\right.$ $1,092.7, p=.338$ ], and the other (two-way and threeway) interactions also were not reliable $(p s>.1)$.

The results indicate that both the tachistoscopic and the search tasks were less difficult than in the former experiments. RTs were faster, slopes were flatter, and there were fewer errors than in the former experiments. As before, the tachistoscopic task yielded fast RTs and few errors. The )( target could be well distinguished from the various distractors.

The findings from the search task again do not suggest an emergent feature property for symmetry. Note that the )( targets had not only vertical but also horizontal symmetry. Still, search slopes were well in the range indicating serial search. Note also that possible other factorssuch as high familiarity or overlearnedness of the stimulus elements, or its overall appearance as a single X-like figure-did not result in parallel search.

In contrast, in the closure condition, search slopes were close to the range usually taken to suggest parallel search (0-10 msec per item; see, e.g., Treisman \& Gor- 


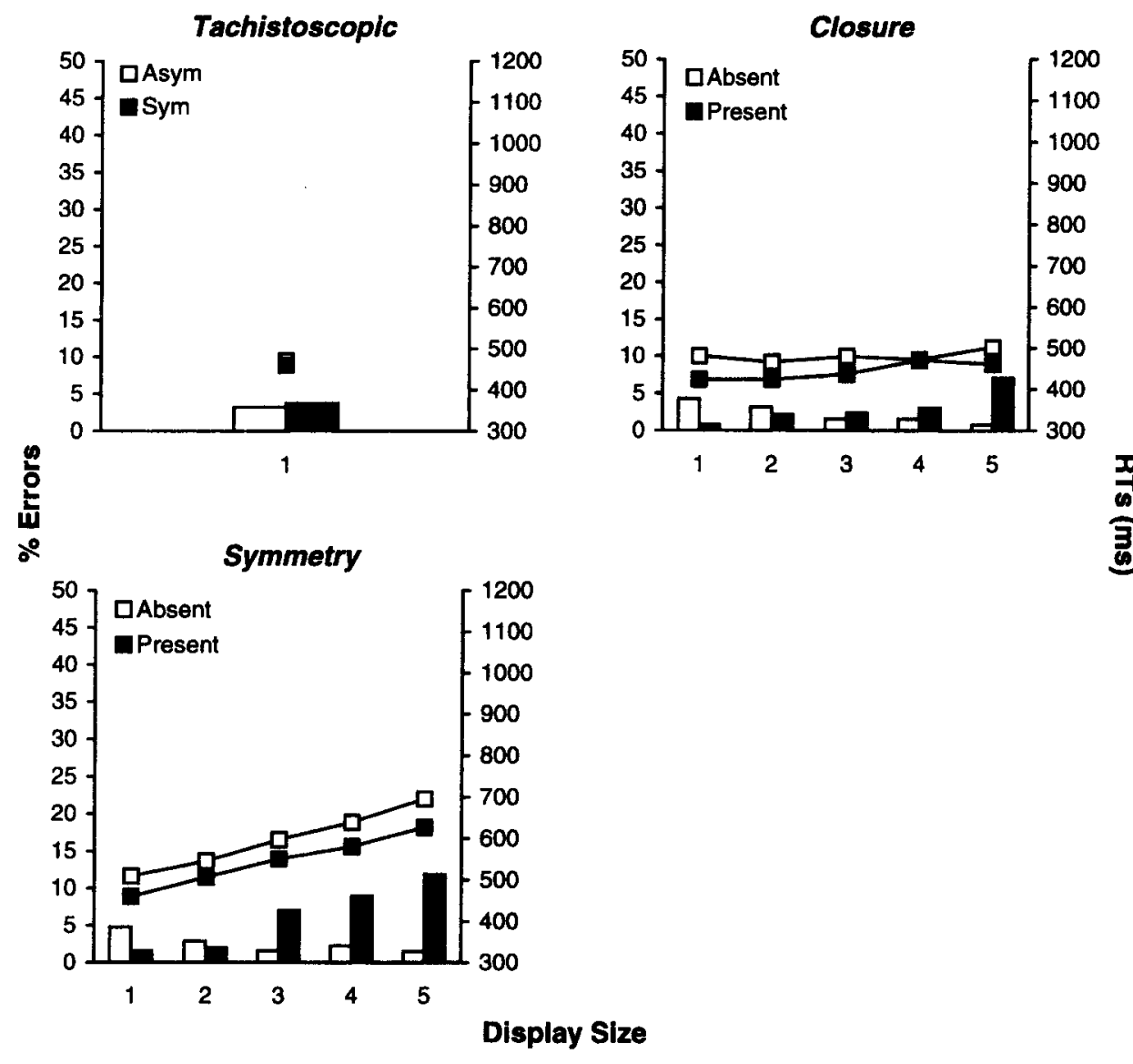

Figure 8. Results from the tachistoscopic and visual search tasks of Experiment 4. The columns correspond to error percentages, the small squares to $R T s$.

mican, 1988), at least for absent trials. This implies that complexity cannot account for the absence of an emergent symmetry effect in the symmetry condition, since the number and type of stimulus elements were exactly the same. It also implies that some feature of the () target provides a parallelly detectable cue-that is, some property other than symmetry, or some property combined (strongly interacting) with it. A good candidate seems, indeed, to be closure (Pomerantz \& Pristach, 1989; Treisman \& Paterson, 1984; Treisman \& Schmidt, 1982 ), but convexity also could play a role. The important point for now is that symmetry on its own does not provide such a cue.

A somewhat puzzling but not uncommon (see, e.g., Kaptein, Theeuwes, and Van der Heijden, 1995) result is the absence of a target $X$ display size interaction in the symmetry condition. There was already a hint of this in the symmetry condition of Experiment 3 and the asymmetry condition of Experiment 2. Usually, in the case of serial search, increasing the display size has a double effect on absent trials, relative to present trials, since, on present trials, on average only half the items need to be searched. Perhaps, on absent trials, subjects sometimes quickly and incorrectly (see the error pattern) noticed the absence of something strange. That is, if they could not find anything strange, they decided absent. The opposite-quickly responding present on the basis of something strange - is not useful, because, due to noise in the system, something could be anything and not necessarily the target property (see Kaptein et al., 1995, for a similar explanation).

\section{GENERAL DISCUSSION}

In this study, we investigated whether a single symmetry effortlessly perceived within $120 \mathrm{msec}$ is also effortlessly perceived among multiple other patterns. As we already suggested in the introduction, a complete description of the interaction between symmetry and attention also requires a look at the wholistic level. Were symmetry to guide the visual system in an early stage, it ought to be detected rapidly and effortlessly across a large part of the visual field. We therefore asked the question of whether symmetry is detected in parallel across multiple patterns. The answer turns out to be a clear no.

In all the experiments, each using a different type of stimulus, performance in the tachistoscopic task was 
near perfect. Symmetry detection was always rapid and highly accurate when single patterns were presented off fixation for $120 \mathrm{msec}$. This corroborates earlier findings that the symmetric pattern need not be presented foveally (Saarinen, 1988; Saarinen, Rovamo, \& Virsu, 1990), or aligned with the bilateral symmetry of the nervous system (see, e.g., Corballis \& Beale, 1970). It also counters any argument in terms of low visibility, low discriminability, or the necessity for eye movements in our displays. It further confirms that attention is not deployed in a point-by-point fashion about the axis (Baylis \& Driver, 1994; Julesz, 1971). These findings are, therefore, well in line with Julesz's (1981) definition of effortless preattentive symmetry perception.

Whereas the tachistoscopic task indicates that selection of the individual pattern elements (dots, lines, etc.) is not necessary for symmetry detection, the visual search task shows that selection of the pattern as a whole is. With none of the four types of stimuli did a symmetric target yield the flat search slopes indicative of parallel search. The only exception was the () target in Experiment 4 , but this seems to be mainly attributable to closure effects or the like (Treisman \& Paterson, 1984).

Thus, selective attention has a clear role in symmetry detection: selection of the symmetrical pattern. Note the similarity to face perception: Whereas single faces are parallelly processed as a whole, multiple faces need serial scanning in order for a target face to be found (Nothdurft, 1993).

Other studies also conclude that attention plays an important role in symmetry perception. Wenderoth (1994), for instance, demonstrated that the salience of vertical symmetry, relative to other orientations, is abolished or even reversed by changing their probabilities of occurrence. He showed that, when only $3 \%$ of the symmetries were vertical and the rest fell in between diagonal and horizontal, detection at the oblique and horizontal orientations was highly superior to detection at vertical orientations. Wenderoth argued that attentional strategies were responsible for orientation effects in symmetry perception.

Another study also can be interpreted as indicating the importance of attention in symmetry coding, although it was actually meant to show that symmetry is perceived preattentively. Driver et al. (1992) report the case of a visual neglect patient, C.C., who was shown arrays of six alternating red and green pseudorandom areas. On half the trials, the green shapes were symmetric, whereas the red were asymmetric, and, on the other half, vice versa. When asked which color the figures had, C.C. showed a common effect-that is, when the red areas were symmetric, he reported "red figures" and, similarly, "green figures" with green symmetries. However, when explicitly asked whether the appointed figures were symmetric or not, his responses were at chance level. Driver et al. explained these findings by arguing that symmetry detection must have been preattentive, since C.C. correctly used symmetry to segregate the figures from their background, but that his neglect somehow prevented symme- try to be available for verbal report. But, later, Baylis and Driver $(1994,1995)$ changed the rationale concerning symmetry and figure-ground segmentation slightly. They now hold the view that symmetry detection is a side effect contingent on the outcome of preattentive objectpart decompositions. A symmetric object is characterized by the match in convexity/concavity descriptions of its symmetric sides - that is, such shapes can be unambiguously decomposed into convex parts. Shapes with such convexity matches (either exactly symmetric or not) are normally seen as figures against a background, whereas figures with nonmatching convexities can be interpreted in several ways (see Kanizsa, 1979, for examples). However, this allows us to reverse the argument concerning C.C.: He correctly determined the figures and the background because of intact preattentive part decomposition but failed to explicitly detect symmetry, because attention is required for that!

The discussion above indicates that the interaction between symmetry and segmentation may be quite complex. Indeed, it is hard to think of a symmetric shape without matching part decompositions, which allows arguments to be reversed. Yet, it is in this segmentation domain that we think symmetry may still play a preattentive role - for instance, in more texture-like stimuli. So far, we have mainly considered symmetry per se-that is, as an isolated tag assigned to objects (cf. Biederman, 1987) - but it may be other information, caused by symmetry, that is coded preattentively. For instance, Wolfe and Friedman-Hill (1992) found that symmetry groupings affect visual search. Their task yielded flat slopes when the target stood against a symmetric background but steeper slopes when the target itself formed a symmetric relationship with one of the distractors. These results indicate that it is possible that symmetry is a preattentive grouping mechanism serving to segment one region from the other. In this sense, it may be that, in our experiments, symmetry is indeed calculated in parallel across the visual field but that explicit symmetry information is just not delivered to the higher systems without attention. What could alert the higher systems is the indirect grouping or segmentation information. But since, in our experiments, the stimuli were already segmented into separate objects (i.e., the distractors as well), symmetry could not contribute to this. More research seems, therefore, required. In the meantime, we conclude that it is very hard to judge whether a pattern is symmetric or not without having a glance at it.

\section{REFERENCES}

BarLow, H. B., \& ReEves, B. C. (1979). The versatility and absolute efficiency of detecting mirror symmetry in random dot displays. Vision Research, 19, 783-793.

Baylis, G. C., \& Driver, J. (1994). Parallel computation of symmetry but not repetition within single visual shapes. Visual Cognition, 1, 377-400.

BAYLIS, G. C., \& Driver, J. (1995). Obligatory edge-assignment in vision: The role of figure and part-segmentation in symmetry detection. Journal of Experimental Psychology: Human Perception \& Performance, 21, 1323-1342. 
Bertamini, M., Friedenberg, J. D., \& Kubovy, M. (1997). Detection of symmetry and perceptual organization: The way a lock-and-key process works. Acta Psychologica, 95, 119-140.

BIEDERMAN, I. (1987). Recognition-by-components: A theory of human image understanding. Psychological Review, 94, 115-147.

Broadbent, D. E. (1958), Perception and communication. London: Pergamon.

BUNDESEN, C. (1990). A theory of visual attention. Psychological ReView, 97, 523-547.

Clement, D. E., \& Weiman, C. F. R. (1970). Instructions, strategies, and pattern uncertainty in a visual discrimination task. Perception \& Psychophysics, 7, 333-336.

Corballis, M. C., \& Beale, I. L. (1970). Bilateral symmetry and behavior. Psychological Review, 77, 451-464.

Donnelly, N., Humphreys, G. W., \& Riddoch, M. J. (1991). Parallel computation of primitive shape descriptions. Journal of Experimental Psychology: Human Perception \& Performance, 17, 561-570.

Driver, J., Baylis, G. C., \& Rafal, R. (1992). Preserved figure-ground segregation and symmetry detection in visual neglect. Nature, $\mathbf{3 6 0}$, 73-75.

Duncan, J., \& Humpureys, G. W. (1989). Visual search and stimulus similarity. Psychological Review, 96, 433-458.

ENNs, J. T. (1990). Three-dimensional features that pop out in visual search. In D. Brogan (Ed.), Visual search (pp. 37-45). London: Taylor \& Francis.

FISCHER, B. (1986). The role of attention in the preparation of visually guided eye movements in monkey and man. Psychological Research, 48, 251-257.

Hoffman, D. D., \& Richards, W. A. (1984). Parts of recognition. Cognition, 18, 65-96.

Julesz, B. (1971). Foundations of cyclopean perception. Chicago: University of Chicago Press

JULESZ, B. (1981). Figure and ground perception in briefly presented isodipole textures. In M. Kubovy \& J. Pomerantz (Eds.), Perceptual organization (pp. 27-54). Hillsdale, NJ: Erlbaum.

Kanizsa, G. ( 1979). Organization in vision. New York: Praeger.

Kaptein, N. A., Theeuwes, J., \& Van der Heidden, A. H. C. (1995). Search for a conjunctively defined target can be selectively limited to a color-defined subset of elements. Journal of Experimental Psychology: Human Perception \& Performance, 21, 1053-1069.

KoFfKa, K. (1935). Principles of gestalt psychology. New York: Harcourt, Brace \& World.

LOCHER, P. J., \& NoDINE, C. F. (1987). Symmetry catches the eye. In J. K. O'Regan \& A. Lévy-Schoen (Eds.), Eye movements: From physiology to cognition (pp. 353-361). Amsterdam: Elsevier.

LOCHER, P. J., \& WAGEMANS, J. (1993). Effects of element type and spatial grouping on symmetry detection. Perception, 22, 565-587.

Mack, A., Tang, B., Tuma, R., KahN, S., \& Rock. I. (1992). Perceptual organization and attention. Cognitive Psychology, 24, 475-501.

MarR, D. (1982). Vision. San Francisco: Freeman.

Maxwell, S. E., \& Delaney, H. D. (1990). Designing experiments and analyzing data. Pacific Grove, CA: Brooks/Cole

Nothourft, H. - C. (1993). Faces and facial expressions do not pop out. Perception, 22, 1287-1298.

PALMER, S. E. (1983). The psychology of perceptual organization, a transformational approach. In J. Beck, B. Hope, \& A. Rosenfeld (Eds.), Human and machine perception (pp. 269-339). New York: Academic Press.

Palmer, S. E., \& Hemenway, K. (1978). Orientation and symmetry: Effects of multiple, rotational, and near symmetries. Journal of Experimental Psychology: Human Perception \& Performance, 4, 69l-702.

Pascal, B. (1950). Pascal's Pensées (H. F. Stewart, Trans.). London: Routledge \& Kegan Paul. (Original work published 1658)

Pomerantz, J. R., \& Garner, W. R. (1973). Stimulus configuration in selective attention tasks. Perception \& Psychophysics, 14, 565-569.

Pomeranjz, J. R., \& Kubovy, M. (1986). Theoretical approaches to perceptual organization. In K. R. Boff, L. Kaufman, \& J. P. Thomas (Eds.), Handbook of perception and human performance (Vol. 2, pp. 36.1-36.46). New York: Wiley.
Pomerantz, J. R., \& Pristach, E. A. (1989). Emergent features, attention, and perceptual glue in visual form perception. Journal of Experimental Psychology: Human Perception \& Performance, 15. 635-6.49.

Pomerantz, J. R., Sager, L. C., \& Stoever, R. J. (1977). Perception of wholes and of their component parts: Some configural superiority effects. Journal of Experimental Psychology: Human Perception \& Performance, 3, 422-435.

Pomerantz, J. R., \& Schwaitzberg, S. D. (1975). Grouping by proximity: Selective attention measures. Perception \& $P$ sychoph $v$ sics, 18, 355-361.

PosNer, M. I. (1980), Orienting of attention. Quarterly Journal of Experimental Psychology, 32, 3-25.

Quinlan, P., \& Humphreys, G. W. (1993). Perceptual frames of reference and two-dimensional shape recognition: Further examination of internal axes. Perception, 22, 1343-1364.

Rock, I. (1983). The logic of perception. Cambridge, MA: MIT Press.

Rock, I., \& Leaman, R. (1963). An experimental analysis of visual symmetry. Acta Psychologica, 21, 171-183.

ROYER, F. L. (1981). Detection of symmetry. Journal of Experimental Psychology: Human Perception \& Performance, 7, 1186-1210.

SAARINEN, J. (1988). Detection of mirror symmetry in random dot patterns at different eccentricities. Wision Research, 28, 755-759.

SaARInen, J., Rovamo, J., \& Virsu, V. (1990). Perception of spatial structure in peripheral vision. In D. Brogan (Ed.), Visual search (pp. 297-301). London: Taylor \& Francis.

Sebrechts, M. M., \& GARNER, W. R. (1981). Stimulus-specific processing consequences of pattern goodness. Memory \& Cognition, 9 , 41-49.

TownsEnd, J. T. (1972). Some results concerning the identifiability of parallel and serial processes. British Journal of Mathematical \& Statistical Psychology, 25, 168-199.

Treisman, A., \& Gelade, G. (1980). A feature-integration theory of attention. Cognitive Psychology, 12, 97-136.

Treisman, A., \& Gormican, S. (1988). Feature analysis in early vision: Evidence from search asymmetries. Psychological Revien, 95, 1548.

Treisman, A., \& PATERSON, R. (1984). Emergen features, attention, and object perception. Journal of Experimental Psychology: Human Perception \& Performance, 10, 12-31.

TREISMAN, A., \& SCHMIDT, H. (1982). Illusory conjunctions in the perception of objects. Cognitive Psychology, 14, 107-141.

Treisman, A., \& SOUTHER, J. (1985). Search asymmetry: A diagnostic for preattentive processing of separable features. Journal of Experimental Psychology: General, 114, 285-310.

VETTER, T., \& Poggio, T. (1995). Symmetric 3D objects are an easy case for 2D object recognition. Spatial Vision, 8, 443-453.

WaGEMANS, J. (1993). Skewed symmetry: A nonaccidental property used to perceive visual forms. Journal of Experimental Psychology: Human Perception \& Performance, 19, 364-380.

Wagemans. J. (1995). Detection of visual symmetries. Spatial Vision, 9, 9-32.

WaGEMaNs, J., VAN GOOL, L., \& D'YDEWALle, G. (1990). Visual search in dot-patterns with bilateral and skewed symmetry. In D. Brogan (Ed.), Visual search (pp, 99-114). London: Taylor \& Francis.

WAGEMANS, J., VAN GOOL, L., \& D'Y DEWALle, G. (1992). Orientational effects and component processes in symmetry detection. Quarterly Journal of Experimental Psychology, 44A, 475-508.

Wenderoth, P. (1994). The salience of vertical symmetry. Perception, 23, $221-236$.

WENDEROTH, P. (1995). The role of pattern outline in bilateral symmetry detection with briefly flashed dot patterns. Spatial Vision, 9, 5777 .

WoLfE, J. M. (1994). Guided Search 2.0: A revised model of visual search. Psychonomic Bulletin \& Review, 1, 202-238.

Wolfe, J. M., \& FrJedman-Hill, S. R. (1992). On the role of symmetry in visual search. Psychological Science, 3, 194-198

YANTIS, S., \& JONIDES, J. (i984), Abrupt visual onsets and selective attention: Voluntary versus automatic allocation. Joumal of Exyerimental Psychology: Human Perception \& Perfosmance. 16. I I ! - 134 
Yeshurun, Y., Reisfeld, D., \& Wolfson, H. (1992). Symmetry: A context free cue for foveated vision. In H. Wechsler (Ed.), Neural networks for perception (Vol. 1, pp. 477-491). London: Academic Press.

\section{NOTES}

1. A reviewer remarked that the notions chooses to attend and emergent feature are somewhat contradictory, since the first implies the intervention of a top-down (executive) control, whereas the second im- plies (automatic) self-organization. Granted, but this is the way Pomerantz sees it, and he has found some evidence for it as well.

2. Where degrees of freedom are fractioned, a Greenhouse-Geisser epsilon correction for sphericity violations has been applied, following Maxwell and Delaney's (1990) recommendations.

(Manuscript received June 23, 1997;

revision accepted for publication November 11, 1997.) 